\title{
Processing and characterization of $\alpha$-elastin electrospun membranes
}

\author{
J. Araujo • J. Padrão $\cdot$ J.P. Silva $\cdot$ F. Dourado • \\ D.M. Correia • G. Botelho · J.L. Gomez Ribelles • \\ S. Lanceros-Méndez $\cdot$ V. Sencadas
}

Received: 11 July 2013 / Accepted: 12 September 2013 / Published online: 26 September 2013

(C) Springer-Verlag Berlin Heidelberg 2013

\begin{abstract}
Elastin isolated from fresh bovine ligaments was dissolved in a mixture of 1,1,1,3,3,3-Hexafluoro-2-propanol and water were electrospun into fiber membranes under different processing conditions. Fiber mats of randomly and aligned fibers were obtained with fixed and rotating ground collectors and fibrils were composed by thin ribbons whose width depends on electrospinning conditions; fibrils with $721 \mathrm{~nm}$ up to $2.12 \mu \mathrm{m}$ width were achieved. After crosslinking with glutaraldehyde, $\alpha$-elastin can uptake as much as $1700 \%$ of PBS solution and a slight increase on fiber thickness was observed. The glass transition temperature of electrospun fiber mats was found to occur at $\sim 80^{\circ} \mathrm{C}$. More-
\end{abstract}

J. Araujo · J. Padrão · J.P. Silva · F. Dourado

Institute for Biotechnology and Bioengineering, Centre for

Biological Engineering, University of Minho, Campus Gualtar, 4710-057 Braga, Portugal

D.M. Correia · S. Lanceros-Méndez · V. Sencadas ( $)$ Centro/Departamento de Física da Universidade do Minho, Campus de Gualtar, 4710-057 Braga, Portugal

e-mail:vsencadas@ fisica.uminho.pt

D.M. Correia · G. Botelho

Dept. Química, Centro de Química, Universidade do Minho, Campus de Gualtar, 4710-057 Braga, Portugal

J.L. Gomez Ribelles

Center for Biomaterials and Tissue Engineering, Universitat Politècnica de València, Camino de Vera s/n, 46022 Valencia, Spain

J.L. Gomez Ribelles

Ciber en Bioingeniería, Biomateriales y Nanomedicina (CIBER-BBN), Valencia, Spain

V. Sencadas

Escola Superior de Tecnologia, Instituto Politécnico do Cávado e do Ave, Campus do IPCA, 4750-810, Barcelos, Portugal over, $\alpha$-Elastin showed to be a perfect elastomeric material, and no mechanical hysteresis was found in cycle mechanical measurements. The elastic modulus obtained for random and aligned fibers mats in a PBS solution was $330 \pm 10 \mathrm{kPa}$ and $732 \pm 165 \mathrm{kPa}$, respectively. Finally, the electrospinning and cross-linking process does not inhibit MC-3T3E1 cell adhesion. Cell culture results showed good cell adhesion and proliferation in the cross-linked elastin fiber mats.

\section{Introduction}

Collagen and elastin fibers are responsible for the elastic properties of several tissues. Elastin is the most abundant protein in the extracellular matrix present in tissues where elasticity is a necessary property. Elastin works as an energy storing fiber in lungs, heart, and large blood vessels, providing flexibility and resilience to the skin, bronchi, trachea, tendons, and intestine. Elastin can be also found in high concentrations in some cartilage tissues [1-4].

Elastin is synthesized from the assembly of several monomers of tropoelastin through cross-linking in the extracellular matrix. Tropoelastin is a linear peptide with approximately $70 \mathrm{kDa}$ with both hydrophobic and hydrophilic regions $[3,5,6]$. The hydrophilic sequences of tropoelastin are rich in lysine $(\mathrm{K}$, representing, in average, $5 \%$ of the whole amino acid composition of tropoelastin) that is responsible for the cross-linking. The hydrophobic regions are responsible for the elasticity, comprising repetitive sequences of amino acid residues of variable length $[3,7,8]$.

The insolubility of the mature elastin fibers has been a major drawback for its research, and soluble alternatives 
have been used for the study of its properties. These include tropoelastin, $\alpha$-elastin, and k-elastin (the products of acid and alkali degradation of elastin, respectively), and ELPs (elastin-like polymers) synthesized chemically or by heterologous production through genetic engineered organisms (mainly bacteria) [8-13]. These materials possess elastic moduli equivalent to the elastin fibers, besides being biocompatible and presenting the ability to coacervate at temperatures around $37{ }^{\circ} \mathrm{C}[9,10]$. Coacervation occurs due to the increase in the order of the peptides as the temperature rises. This shift from soluble at low temperatures to insoluble at higher temperatures is named inverse temperature transition [8].

Elastin is an excellent biomedical raw material due to its mechanical properties, durability, and biocompatibility. However, purified elastin is insoluble as it is heavily crosslinked and, consequentially, it is highly difficult to manipulate as a biomaterial [14].

Electrospinning has demonstrated to be a suitable method for the synthesis of submicron- or nanofibers from a broad set of polymer solutions. This technique is relatively versatile, simple, fast, and efficient [15]. Elastin was successfully electrospun for applications in tissue engineering $[14,16-18]$.

$\alpha$-elastin is very similar to tropoelastin, having a similar molecular mass and physico-chemical properties. Tropoelastin has the amino acid sequence of $\alpha$-elastin but it lacks the cross-links desmosine and isodesmosine. Instead, it has high lysine content, which is the precursor of desmosine cross-links [19]. The protein's soluble fractions are typically derived either as fragmented elastin in the form of $\alpha$ and k-elastin, which are very similar to the elastin precursor $[13,20]$.

Weiss and coworks performed extensive work in recombinant human tropoelastin, forming a polymer with similar mechanical and cell interactive properties to those of native elastin. It was demonstrated that human tropoelastin is able to form synthetic hydrogels suitable for tissue engineering applications [21]. It was also shown that the material can be electrospun to give flat, ribbon-like fibers with dimensions close to those found for natural elastic fibers [22].

The aim of the present work is to produce aligned and randomly oriented isolated $\alpha$-elastin electrospun membranes from bovine ligamentum nuchae. The effect of electrospinning parameters in fiber morphology and physical characteristics-was studied. Further, the swelling degree of the membranes at room temperature and at $37^{\circ} \mathrm{C}$ was characterized and the effect PBS solution $(\mathrm{pH}=7.4)$ on fiber geometry was assessed. Mechanical performance of aligned and random distributed fibers was studied for strains up to $50 \%$. The suitability of the produced membranes for biomedical applications was observed by in vitro cell viability studies performed with mouse embryo fibroblast 3T3 cells.

\section{Experimental}

Elastin extraction Elastin was obtained from fresh bovine ligamentum nuchae. The ligament was subjected to four washes with $1 \% \mathrm{NaCl}$ and the supernatant discarded. The methodology used for the purification of elastin has been previously described by Gotte et al. [23]. Briefly, it consists on successive washing treatments (1 hour at room temperature each) with a solution of $0.5 \mathrm{M} \mathrm{NaOH}$ under vigorous agitation. This process was repeated four more times and, at the end of each rinsing, the alkaline solution was replaced by a new one. The fragmented ligament was subsequently subjected to autoclaving $\left(120{ }^{\circ} \mathrm{C}\right.$ for $\left.20 \mathrm{~min}\right)$. The mixture was then transferred to a solution ethanol-ether $50 \%(\mathrm{v} / \mathrm{v})$ and placed under constant agitation for about 20 minutes at room temperature. After this period, the solution was discarded and the ligament subjected to oven-drying at $55^{\circ} \mathrm{C}$, yielding a powder.

The partial hydrolysis of elastin was based on the procedure described by Partridge et al. [24]. Elastin was treated with $0.25 \mathrm{M}$ oxalic acid (ratio of $1 \mathrm{~g}$ elastin: $7.5 \mathrm{ml}$ acid) at $100{ }^{\circ} \mathrm{C}$ for 1 hour with vigorous stirring. The supernatant was removed and the treatment was repeated to the precipitate 4 more times. Afterward, the combined supernatants were centrifuged for 10 minutes at $9000 \mathrm{xg}$ at $4{ }^{\circ} \mathrm{C}$ to remove any residual solids. The resulting supernatant (rich in $\alpha$-elastin), was dialyzed for 4 days at room temperature against distilled water, using a cellulose dialysis membrane with a cut off of $1 \mathrm{kDa}$. Finally, the dialyzed material was subsequently lyophilized.

Once obtained, $\alpha$-elastin enriched powder was dissolved in a mixture of 1,1,1,3,3,3-Hexafluoro-2-propanol (HFIP, $\geq 99 \%$, Sigma Aldrich) and ultra-pure water $(9 / 1 \mathrm{vol} / \mathrm{vol})$ to achieve a final polymer concentration of $20 \mathrm{wt} \%$. Complete dissolution was achieved at room temperature with constant stirring. This solution was used in the electrospinning procedure.

Electrospinning Polymer solution was placed in a commercial plastic syringe $(10 \mathrm{ml})$ fitted with a steel needle. Electrospinning was conducted at different applied electric fields with a high voltage power supply from Glassman (model PS/FC30P04). A syringe pump (from Syringepump) was used to feed the polymer solutions into the needle tip and the electrospun fibers were collected in a grounded collecting plate (random fibers) and in a drum collector at $750 \mathrm{rpm}$ (aligned fibers).

Cross-linking Electrospun fibrous mats of $\alpha$-elastin and $20 \mathrm{~mL}$ of glutaraldehyde (GA, $50 \%$ water, Fisher) were placed into a chamber under vacuum, promoting the formation of GA vapor and to induce sample cross-linking. 
Characterization Electrospun fibers were coated with a thin gold layer using a sputter coating (Polaron, model SC502) and their morphology was analyzed using a scanning electron microscopy (SEM) (Cambridge, Leica) with an accelerating voltage of $15 \mathrm{kV}$. Fiber average diameter and distribution was calculated over approximately 50 fibers using the SEM micrographs (2000× magnification) and ImageJ software [25].

Cryo-SEM micrographs were obtained using a cryogenic fixture attached to a JEOL JSM 5410 equipment. Fully swollen samples were transferred to a cryogenic chamber, frozen in liquid nitrogen and ice crystals were sublimed. The frozen samples were subsequently coated with gold in-situ.

Tensile tests were performed in a Seiko TMA/SS6000 thermo-mechanical analyzer, in the tensile mode at a test speed of $0.5 \mathrm{~mm} \cdot \mathrm{min}^{-1}$ on $4 \times 0.5 \mathrm{~cm}^{2}$ rectangular samples, with a thickness around $50 \mu \mathrm{m}$. The mechanical experiments where performed in oriented and randomly aligned fiber samples at $37^{\circ} \mathrm{C}$. Infrared measurements (FTIR) were performed at room temperature in an ABB FTLA 2000 apparatus from 4000 to $500 \mathrm{~cm}^{-1}$. Spectra were collected with 10 scans and a resolution of $4 \mathrm{~cm}^{-1}$. For the FTIR measurements, approximately $40 \mathrm{mg}$ of polymer fibers previously dried in a vacuum chamber at $40{ }^{\circ} \mathrm{C}$ until constant weight were mixed with $120 \mathrm{mg}$ potassium bromide $(\mathrm{KBr})$. Approximately $40 \mathrm{mg}$ of this mixture were placed into a mold and compacted in order to obtain a disk, with further drying at $40{ }^{\circ} \mathrm{C}$ in a vacuum chamber for at least 72 hours before analysis.

Differential scanning calorimetry (DSC) measurements were performed in a Mettler-Toledo DSC28e apparatus with a heating rate of $10{ }^{\circ} \mathrm{C} \cdot \mathrm{min}^{-1}$. The samples were cut into small pieces from the membrane middle region and placed into $40 \mu \mathrm{L}$ aluminum pans. All experiments were carried out using nitrogen as purge gas.

Swelling behavior The swelling behavior was performed in circular samples of $\sim 10 \mathrm{~mm}$ diameter by gravimetric method. Each sample, after submersion in phosphate buffer saline solution (PBS) $(\mathrm{pH}=7.4)$ for different time intervals, was taken out and placed between two pieces of tissue paper to remove excess PBS. The degree of swelling (\%) was calculated according to

Degree of Swelling $(\%)=\frac{\left(W_{\mathrm{st}}-W_{\mathrm{dt}}\right)}{W_{\mathrm{dt}}} \times 100$,

where $W_{\text {st }}$ denotes the mass of the sample in its wet state after submersion in a PBS and $W_{\mathrm{dt}}$ is the mass of the sample in its dried state.

Cell viability circular $\alpha$-elastin membranes with $13 \mathrm{~mm}$ of diameter were immersed in $70 \%$ ethanol for $30 \mathrm{~min}$ for sterilization purposes. Membranes were then thoroughly washed with sterile phosphate buffered saline (PBS) to eliminate any residual ethanol. Mouse embryo fibroblast
$3 \mathrm{~T} 3$ cells were cultivated in Dulbecco's Modified Eagle's medium (DMEM) (Biochrom), containing $10 \%$ newborn calf serum (Invitrogen) and $1 \%$ of penicillin/streptomycin at $37{ }^{\circ} \mathrm{C}$ in a humidified atmosphere containing $5 \% \mathrm{CO}_{2}$.

For cell viability studies, 3T3 fibroblasts were seeded on the $\alpha$-elastin membranes in 24-well plates with a cell density of $1.2 \times 10^{4}$ cells/well for 3 days. The total cell number adhered to each $\alpha$-elastin membrane was quantified in a Neubauer chamber and viable cells were distinguished from nonviable ones by trypan blue exclusion dye.

\section{Results and discussion}

3.1 Effect of electrospinning parameters on fiber and fiber mat morphology

Electrospun fiber morphology, size, and distribution is affected by several experimental parameters, including initial polymer solution, solution concentration and polymer molecular mass. Moreover, jet formation and solvent evaporation rate are influenced by polymer feed rate, needle diameter, applied electric field, and processing temperature [15, 26, 27].

As indicated before, $\alpha$-elastin obtained from a fresh bovine ligamentum nuchae was dissolved in a blend of HFIP/ultra-pure water with a polymer/solvent concentration of 20/80 (wt \%) and electrospun into a grounded collector in order to study the influence of the electrospinning parameters on fiber geometry, size, and distribution (Fig. 1). The obtained electrospun $\alpha$-elastin fibers showed a ribbon configuration instead of a cylindrical shape characteristic of other polymer systems such as chitosan [28], poly(vinylydene fluoride) [27], and copolymers [29] or poly(L-lactid acid) [30], among others [15].

This morphology is explained by the formation of a thin polymer skin on the liquid jet as a result of solvent evaporation at the jet surface, thereby resulting in a thin layer of solid skin with a liquid core, prevent fiber to buckling. According to Arinstein and Zussman [31] buckling can occur when only after evaporation of portion of the trapped solvent, that will result in a pressure drop across the fiber, whereby the external pressure becomes higher than the internal pressure and the tubular fiber is able to deform. During the course of tube collapse, the initial circular cross section turns into an elliptical shape and thereafter into ribbon-like structures [26, 32]. This ribbon morphology was observed in the electrospun $\alpha$-elastin fibers (Fig. 1) independently of the fiber collecting procedure, i.e., static or rotating collector.

The applied electric field is the key issue of the electrospinning process. The formation of thin fibers is mainly achieved by the stretching and acceleration of the jets promoted by the high electric field [27, 33]. High electric fields 
Fig. $1 \alpha$-elastin electrospun membranes obtained at a feed rate of $1 \mathrm{~mL} \cdot \mathrm{h}^{-1}$, a needle inner diameter of $0.5 \mathrm{~mm}$ and an electric field of:

(a) $0.79 \mathrm{kV} \cdot \mathrm{cm}^{-1}$,

(b) $1.05 \mathrm{kV} \cdot \mathrm{cm}^{-1}$

(c) $1.58 \mathrm{kV} \cdot \mathrm{cm}^{-1}$, and

(d) aligned fiber mat obtained at

$1.05 \mathrm{kV} \cdot \mathrm{cm}^{-1}$
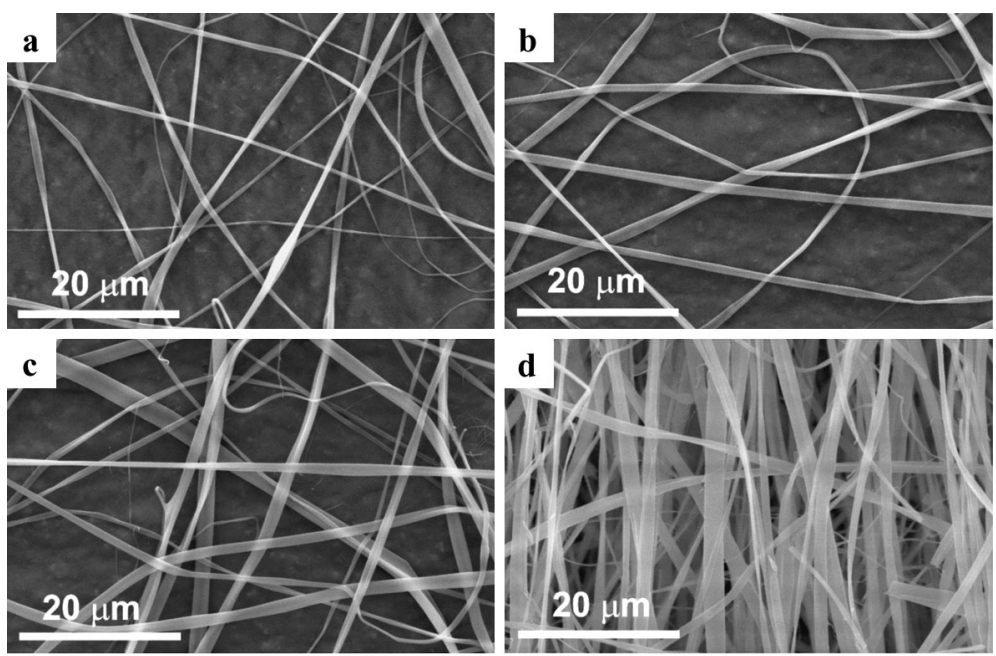

Fig. 2 Influence of electrospinning parameters on $\alpha$-elastin electrospun membranes: (a) electric field (feed rate of $1 \mathrm{~mL} / \mathrm{h}$, and needle inner diameter of $0.5 \mathrm{~mm}$ ),

(b) feed rate (electric field of $1.05 \mathrm{kV} / \mathrm{cm}$ and needle inner diameter of $0.5 \mathrm{~mm}$ ), and (c) needle inner diameter (electric field of $1.05 \mathrm{kV} / \mathrm{cm}$ and a feed rate of $1 \mathrm{~mL} / \mathrm{h}$ )
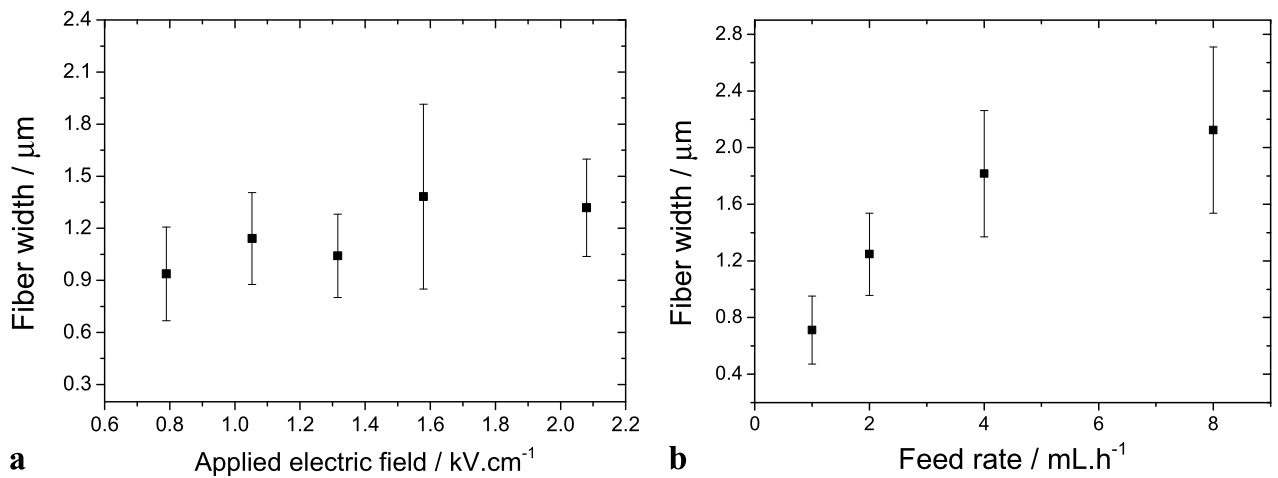

will result in an increase on jet velocity and higher elongation forces. Consequently, it has been generally reported that the diameter of the fibers becomes gradually smaller with increasing applied voltages [34-37]. Moreover, as observed in the present experiments and also in some other cases reported in the literature, increasing applied voltage also affects other processing parameters such as the traveling time of the jet, which has the opposite effect on the fiber diameter [38]. Further, increasing the applied electric field often enhances jet instability, resulting in a broader distribution of the fiber diameters [27, 35, 39] by the formation of fiber branches, with smaller jets being ejected from the primary one, which can be comparable to the ejection of an initial jet from the surface of a charged droplet [26]. In the present work, the variation of fiber average width with increasing voltage is modest (Fig. 2a), demonstrating that this parameter is not particularly critical in the preparation of the electrospun fiber mats. On the other hand, increased fiber width was observed with increasing feed rate for an applied electric field of $1.05 \mathrm{kV} \cdot \mathrm{cm}^{-1}$. The feed rate determines the amount of solution that is available for the electrospinning process at an applied electric field. Increasing the feed rate from $0.5 \mathrm{~mL} \cdot \mathrm{h}^{-1}$ to $8 \mathrm{~mL} \cdot \mathrm{h}^{-1}$ promotes an increase of fiber width in the as-spun samples from $721 \pm 240 \mathrm{~nm}$ up 
Fig. 3 (a) $\alpha$-elastin electrospun membranes swelling index and (b) morphology of the elastin fibers after $4 \mathrm{~h}$ immersion in PBS at room temperature

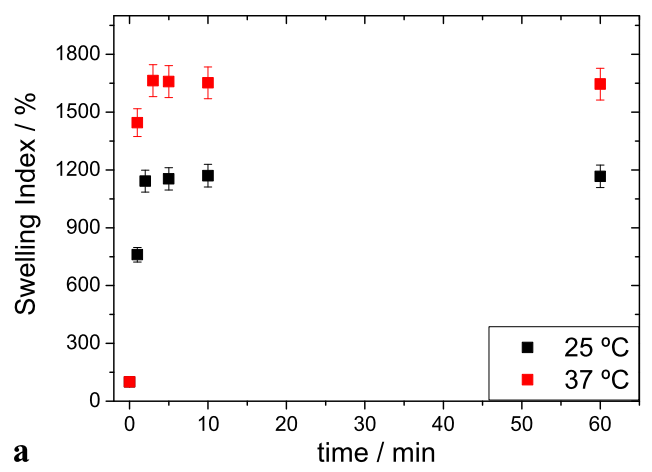

to $2.12 \pm 0.59 \mu \mathrm{m}$. Increasing the feed rate leads to a larger volume of polymer solution that has to be drawn from the needle, which in turn, will increase the solvent evaporation time and, therefore, the larger polymer crystallization time, resulting in fibers with larger widths and a broad size distribution (up to a feed rate of $4 \mathrm{~mL} \cdot \mathrm{h}^{-1}$, Fig. $2 \mathrm{~b}$ ).

The needle inner diameter also plays an important role in fiber diameter and distribution (Fig. 2c). It has been demonstrated that a smaller internal diameter reduces clogging while preventing the formation of beads on electrospun fibers and that this effect could be a consequence of less exposure of the solution to the atmosphere during electrospinning [40]. For $\alpha$-elastin, it was observed that increasing the needle inner diameter promotes a higher fiber width and a broad size distribution (Fig. 2c). This result suggests that with increasing the inner diameter of the needle the surface tension at the needle tip for an applied voltage decreases, resulting in a smaller Coulomb force required to cause jet initiation. As a result, the acceleration of the jet increases and decreases the time for the solution to be stretched and elongated before it is collected. As a consequence, electrospun fibers with higher width were obtained for needles with higher internal diameter (Fig. 2c).

Hydrogels, especially those derived from electrospun fibers, have shown large potential for biomedical applications due to their water retention capacity [13]. The swelling ability of the membrane or scaffold also plays an important role during in vitro culture. When the porous hydrogel membrane is capable of swelling, it increases pore size thus facilitating the cells not only to attach but also to migrate inside the scaffolds and grow in a three-dimensional environment during in vitro culture studies.

Hereby, the $\alpha$-elastin electrospun fiber mats were crosslinked with glutaraldehyde vapor for $24 \mathrm{~h}$ in order to achieve a stable membrane, maintaining thus the structural integrity in aqueous environment. Phosphate buffered saline solution (PBS, $\mathrm{pH}=7.4$ ) was used to study the swelling behavior of $\alpha$-elastin (Fig. 3). The sample was immersed in PBS for different time intervals and the evolution of the mass was measured. It was experimentally observed that uncrosslinked electrospun fiber mats dissolved completely almost instantly when in contact with PBS or water, while the cross- linked samples showed a remarkable swelling degree after 10 min of immersion in PBS (Fig. 3a). At room temperature, the swelling index of the electrospun fiber mats crosslinked with GA was of $\sim 1200 \%$. However, at conditions above coacervation $\left(37^{\circ} \mathrm{C}\right)$, the swelling index showed an increase, reaching a maximum value of $\sim 1700 \%$ (Fig. 3a).

The swelling degree is dependent of the cross-linking density, the affinity between the polymer and external solution, the volume of the structural unit, the fixed charge per unit of volume of the polymer, and the ionic strength of the external solution [41]. Typically, during cross-linking there is a destruction of the crystalline part of the polymer and a more irregular and amorphous phase is obtained [28]. On the other hand, elastin is known to acquire a more organized three dimensional structure at temperatures above coacervation $[8,9]$ with more free space between the polymer chains, thus increasing the capacity of the polymer membrane to retain the PBS solution. Moreover, at $\mathrm{pH}$ around 7, the ionization of the free amine groups in cross-linked $\alpha$-elastin fiber mats increases and the concentration of the ionic groups in the polymer network increases, resulting in an appreciable increase in the water retention [42]. Figure $3 b$ shows the typical microstructure of the $\alpha$-elastin fibers after complete swelling in a PBS solution at room temperature. When compared to the as-spun fiber mats, the ribbon structure of the fibers is still present, but an increase in the thickness of individual fibers was observed (Fig. 3b). This indicates that $\alpha$ elastin retains higher amounts of PBS solution inside of the polymer fibers, contributing for the higher swelling index presented by this material. Ceccorulli et al. [43] suggested that loosely bound water molecules are inserted in preexistent hydrogen bonds between the carbonyl groups and the amide hydrogen atoms, and with increasing of the ionization of the amine groups, the water absorption in the $\alpha$-elastin will increase.

The as spun cross-linked fibers show a glass transition at $80{ }^{\circ} \mathrm{C}$ (Fig. 4), nearly independent of the electrospinning conditions contrasting with that at $200{ }^{\circ} \mathrm{C}$ previously determined in a dry sample [44]. This significant difference can be ascribed to small water contents that are trapped from air moisture by fibers due to hygroscopic nature of the polymer, and it behave has a strong plasticizer effect on elastin [44]. 


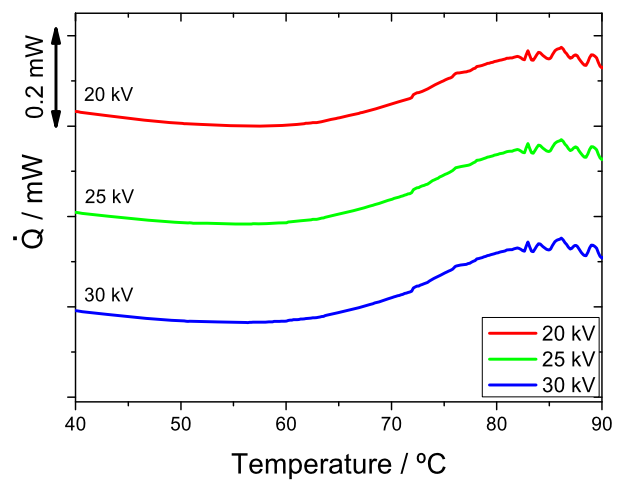

Fig. 4 Differential scanning calorimetry results obtained for $\alpha$-elastin electrospun membranes (feed rate of $1 \mathrm{~mL} \cdot \mathrm{h}^{-1}$, a needle inner diameter of $0.5 \mathrm{~mm}$ and an electric field of $1.05 \mathrm{kV} \cdot \mathrm{cm}^{-1}$ )

Table $1 \alpha$-elastin infrared absorption bands (adapted from [45, 47])

\begin{tabular}{ll}
\hline Wavenumber $\left(\mathrm{cm}^{-1}\right)$ & Characteristic band \\
\hline 3315 & Amide A \\
1656 & Amide I \\
1539 & Amide II \\
1408 & $v(\mathrm{CO})$ \\
1336 & $\delta(\mathrm{CH})$ \\
1305 & $\delta(\mathrm{CH})$ \\
1265 & $\mathrm{C}-\mathrm{O}-\mathrm{C}$ \\
1236 & Amide III $(\beta)$ \\
1165 & $\mathrm{C}-\mathrm{O}$ \\
1104 & $v\left(\mathrm{C}_{\alpha}-\mathrm{N}\right)$ \\
1032 & $v(\mathrm{C}-\mathrm{C})$ \\
966 & $v(\mathrm{C}-\mathrm{C})$ \\
928 & $v\left(\mathrm{C}_{\alpha}-\mathrm{C}\right)(\alpha)$ \\
\hline
\end{tabular}

The main features observed in infrared spectroscopy of proteins are those associated with planar peptidic bond vibrational modes, denominated the amide bands, whose position, width, and intensity are characteristics of the associated vibrational modes and thus of the local geometry of the peptidic chain [45]. FTIR data of $\alpha$-elastin electrospun fibers shows two important regions: one in the region between $1900-900 \mathrm{~cm}^{-1}$, associated to the amide bands mainly induced by $\mathrm{C}=\mathrm{O}$ stretching vibration and the other in the region of $3800-2700 \mathrm{~cm}^{-1}$, which is related with vibrational bands of $\mathrm{OH}, \mathrm{NH}$ and $\mathrm{CH}$ groups (Table 1). The spectra for the samples obtained with different applied electric fields are quite similar: neither vibrational modes are totally suppressed nor new modes seem to appear due to the electrospinning process. The characteristic vibrational bands of amide I, II, and III are observed at $1656 \mathrm{~cm}^{-1}(\mathrm{C}=\mathrm{O}$ stretching), $1539 \mathrm{~cm}^{-1}$ (N-H bending and $\mathrm{C}-\mathrm{N}$ stretching) and $1236 \mathrm{~cm}^{-1}(\mathrm{~N}-\mathrm{H}$ in plane deformation), respectively. When the sample is submitted to the cross-linking process

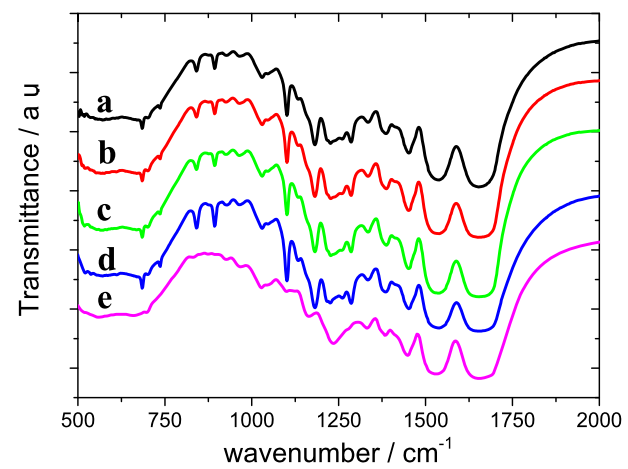

Fig. 5 Infrared spectroscopy of $\alpha$-elastin electrospun membranes obtained with a feed rate of $1 \mathrm{~mL} \cdot \mathrm{h}^{-1}$, a needle inner diameter of $0.5 \mathrm{~mm}$ (a) $15 \mathrm{kV} / \mathrm{cm}$, (b) $20 \mathrm{kV} / \mathrm{cm}$, (c) $25 \mathrm{kV} / \mathrm{cm}$, (d) $30 \mathrm{kV} / \mathrm{cm}$, and (e) electrospun sample obtained with an electric field of $1.05 \mathrm{kV} \cdot \mathrm{cm}^{-1}$ and cross-linked with GA

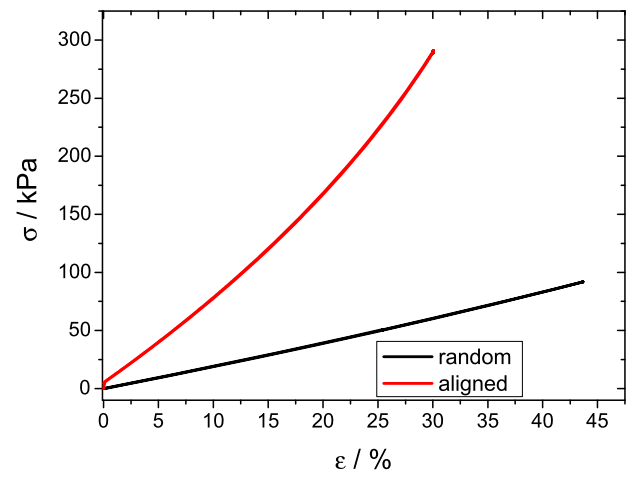

Fig. 6 Typical stress-strain cycles for $\alpha$-elastin electrospun membranes obtained at room temperature (feed rate of $1 \mathrm{~mL} \cdot \mathrm{h}^{-1}$, a needle inner diameter of $0.5 \mathrm{~mm}$, an electric field of $1.05 \mathrm{kV} \cdot \mathrm{cm}^{-1}$ and cross-linked with GA). Curves measured on loading and recovery ramps perfectly superpose each other

in a vapor chamber, some vibrational bands of the $\alpha$-elastin change their intensity; for instance, the vibrational mode at $1236 \mathrm{~cm}^{-1}$, corresponding to the secondary structures of amide III $\beta$-sheets shows a larger absorbance and becomes broader. The absorption band at $1100 \mathrm{~cm}^{-1}$, corresponding to $v\left(\mathrm{C}_{\alpha}-\mathrm{N}\right)$ bond decreases its intensity, suggesting a decrease of the amount of $\alpha$-helical structures present in the cross-linked electrospun fibers [46]. Further, the characteristic bands associated to aromatic tyrosine vibrational modes (854 and $834 \mathrm{~cm}^{-1}$ ) residues disappear upon the cross-linking process (Fig. 5).

\subsection{Mechanical behavior}

Mechanical properties of scaffolds and membranes are one of the key issues for tissue engineering and biomedical applications. The representative quasistatic mechanical behavior for random and aligned $\alpha$-elastin electrospun fibers is presented in Fig. 6. The data were obtained during a continuous deformation cycle (stretching and recover, the last one 
Fig. 7 (a) SEM images of mouse embryo fibroblast 3T3 cells in GA cross-linked $\alpha$-elastin mats after $72 \mathrm{~h}$ culture and (b) Cell density measurements performed with the trypan blue exclusion dye

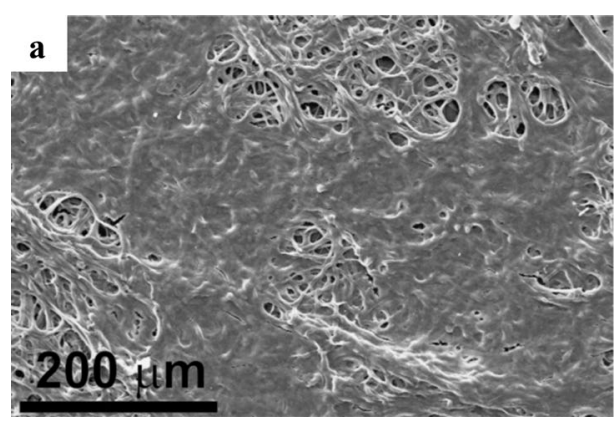

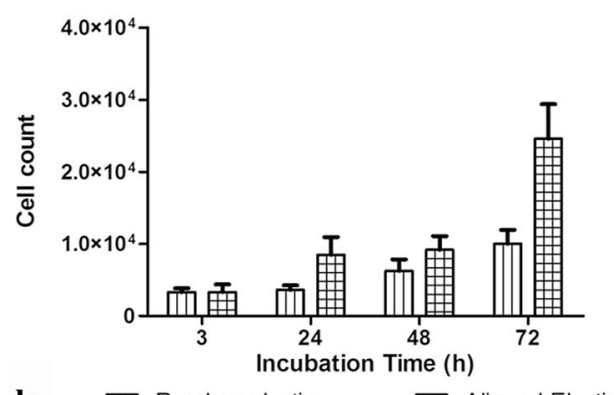

b was performed immediately after the sample arise the deformation imposed previously), demonstrating that for the applied deformation conditions, the material does not present energy losses or mechanical hysteresis, behaving just like a "perfect" elastomer. This mechanical behavior is related to the flexible molecules present in the material that can easily change their shape or conformation when stretched, typically glycine, valine, and proline, which are the most common amino acids present in the longest sequence of the elastin polymer. The elastic modulus $E$ of the electrospun membranes were obtained from

$\sigma=E \varepsilon$

where $\sigma$ is the measured mechanical stress and $\varepsilon$ the applied deformation. The calculated elastic modulus for the random and aligned electrospun membranes is $330 \pm 10 \mathrm{kPa}$ and $732 \pm 165 \mathrm{kPa}$, respectively. The increase in elastic modulus for the oriented electrospun fibers is justified by the high alignment of the fibers in the direction of the applied mechanical load while for the random aligned fibers, when the sample is submitted to a mechanical solicitation, fiber alignment in the direction of the mechanical load will first occur, which contributes for the lower values obtained for the elastic modulus (Fig. 6). The obtained values for the elastic modulus of electrospun $\alpha$-elastin randomly and oriented fibers are higher than those previously observed by Aaron and Gosline [48], that reported an elastic modulus of $110 \mathrm{kPa}$ for randomly oriented nanofibers.

\subsection{Cell culture}

Elastin polypeptide materials display a large potential for tissue and biomedical engineering such as wound dressing, scaffolds or drug delivery applications. Cell seeding experiments were carried out on electrospun random and aligned fiber mats cross-linked with GA. The typical overall morphology of the mouse embryo fibroblast $3 \mathrm{~T} 3$ cells seeded in both $\alpha$-elastin random and aligned fibers can be seen in Fig. 7.

Even though initial cell adhesion showed to be quite low, a considerable increase in the number of viable cells growing on the aligned and random fibers was observed after
$48 \mathrm{~h}$, in comparison with $3 \mathrm{~h}$ (Fig. 7b), suggesting that both scaffolds are suitable for cell growth. Moreover, it is worth mentioning that the number of 3T3 cells was higher in cells cultured in the aligned scaffold than in the random one. This is clearly noticeable especially after 72 hours of cell culture, suggesting that aligned fibers are more suitable for proliferation of fibroblasts than nonoriented scaffolds.

\section{Conclusions}

Elastin was isolated from fresh bovine ligaments, dissolved in mixtures of 1,1,1,3,3,3-Hexafluoro-2-propanol and water and electrospun to produce randomly oriented or aligned mats. Electrospun fibrils have the form of thin ribbons whose width depends on electrospinning conditions; fibrils with $721 \mathrm{~nm}$ up to $2.12 \mu \mathrm{m}$ width can be obtained. The flat shape of the elastin fibrils is explained by the formation of a solid skin in the fibril while travelling from the needle to the collector and a collapse of the fibril when deposited on the collector. Elastin electrospun mats behave as a perfectly elastic elastomer with respect to its mechanical properties. Equilibrium water uptake at $37{ }^{\circ} \mathrm{C}$ reaches $1700 \%$ measured on dry basis. The supports sustain proliferation and viability of 3T3 fibroblasts cultured in monolayer.

Acknowledgements This work is funded by FEDER funds through the "Programa Operacional Factores de CompetitividadeCOMPETE" and by national funds arranged by FCT- Fundação para a Ciência e a Tecnologia, project references NANO/NMed-SD/0156/ 2007, PTDC/CTM-NAN/112574/2009, and PEST-C/FIS/UI607/2011. The authors also thank funding from "Matepro-Optimizing Materials and Processes", ref. "NORTE-07-0124-FEDER-000037", cofunded by the "Programa Operacional Regional do Norte" (ON.2-O Novo Norte), under the "Quadro de Referência Estratégico Nacional" (QREN), through the "Fundo Europeu de Desenvolvimento Regional" (FEDER). The authors also thank support from the COST Action MP1003, 2010 'European Scientific Network for Artificial Muscles'. VS, JP, JS, and DMC thank the FCT for the SFRH/BD/48708/2008, SFRH/BD/ 64901/2009, SFRH/BPD/64958/2009 and SFRH/BPD/63148/2009, and SFRH/BD/82411/2011 grants, respectively. JLGR acknowledges the support of the Spanish Ministry of Science and Innovation through project No. MAT2010-21611-C03-01 (including the FEDER financial support). CIBER-BBN is an initiative funded by the VI National R\&D\&i Plan 2008-2011, Iniciativa Ingenio 2010, Consolider Program, CIBER Actions and financed by the Instituto de Salud Carlos III with assistance from the European Regional Development Fund. 


\section{References}

1. J.E. Wagenseil, R.P. Mecham, Birth defects research, Part C: Embryo today. Reviews 81, 229 (2007). doi:10.1002/bdrc.20111

2. F.W. Keeley, C.M. Bellingham, K.A. Woodhouse, Philos. Trans. R. Soc. Lond. B, Biol. Sci. 357, 185 (2002). doi:10.1098/rstb. 2001.1027

3. G.W. Chalmers, J.M. Gosline, M.A. Lillie, J. Exp. Biol. 202, 301 (1999)

4. B. Li, V. Daggett, J. Muscle Res. Cell Motil. 23, 561 (2002). doi: 10.1023/a:1023474909980

5. J. Uitto, J. Invest. Dermatol. 72, 1 (1979)

6. P. Brown-Augsburger, T. Broekelmann, J. Rosenbloom, R.P. Mecham, Biochem. J. 318, 149 (1996)

7. A.S. Tatham, P.R. Shewry, Trends Biochem. Sci. 25, 567 (2000). doi:10.1016/S0968-0004(00)01670-4

8. D.W. Urry, What Sustains Life? Consilient Mechanisms for Protein-Based Machines and Materials (Springer, Singapore, 2006)

9. B.A. Cox, B.C. Starcher, D.W. Urry, J. Biol. Chem. 249, 997 (1974)

10. J.C. Rodríguez-Cabello, M. Alonso, M.I. Díez, M.I. Caballero, M.M. Herguedas, Macromol. Chem. Phys. 200, 1831 (1999). doi: 10.1002/(sici)1521-3935(19990801)200:8<1831::aid-macp1831> 3.0.co;2-v

11. R. Machado, A.J. Ribeiro, J. Padrão et al., J. Nanopart. Res. 6, 133 (2009). doi:10.4028/www.scientific.net/JNanoR.6.133

12. Z. Indik, H. Yeh, N. Ornstein-Goldstein et al., Proc. Natl. Acad. Sci. 84, 5680 (1987)

13. J.F. Almine, D.V. Bax, S.M. Mithieux et al., Chem. Soc. Rev. 39, $3371(2010)$

14. L. Nivison-Smith, J. Rnjak, A.S. Weiss, Acta Biomater. 6, 354 (2010). doi:10.1016/j.actbio.2009.08.011

15. W.E. Teo, S. Ramakrishna, Nanotechnology 17, R89 (2006)

16. M.S. El-Kurdi, Y. Hong, J.J. Stankus, L. Soletti, W.R. Wagner, D.A. Vorp, Biomaterials 29, 3213 (2008). doi:10.1016/j. biomaterials.2008.04.009

17. J. Stitzel, J. Liu, S.J. Lee et al., Biomaterials 27, 1088 (2006). doi:10.1016/j.biomaterials.2005.07.048

18. L. Buttafoco, N.G. Kolkman, P. Engbers-Buijtenhuijs et al., Biomaterials 27, 724 (2006). doi:10.1016/j.biomaterials.2005.06.024

19. R. Tarnawski, J. Kasperczyk, M. Drózdż, Ups. J. Med. Sci. 98, 53 (1993). doi:10.3109/03009739309179303

20. B. Vrhovski, A.S. Weiss, Eur. J. Biochem. 258, 1 (1998). doi:10. 1046/j.1432-1327.1998.2580001.x

21. S.M. Mithieux, J.E.J. Rasko, A.S. Weiss, Biomaterials 25, 4921 (2004). doi:10.1016/j.biomaterials.2004.01.055

22. M. Li, M.J. Mondrinos, M.R. Gandhi, F.K. Ko, A.S. Weiss, P.I. Lelkes, Biomaterials 26, 5999 (2005). doi:10.1016/j.biomaterials. 2005.03.030

23. L. Gotte, P. Stern, D.F. Elsden, S.M. Partridge, Biochem. J. 87, 344 (1963)
24. S.M. Partridge, H.F. Davis, Biochem. J. 61, 21 (1955)

25. M.D. Abramoff, P.J. Magalhães, S.J. Ram, Biophoton. Int. 11, 36 (2004)

26. S. Ramakrishna, K. Fujihara, W.E. Teo, T.C. Lim, Z. Ma, Introduction to Electrospinning and Nanofibers (World Scientific, Singapore, 2005)

27. C. Ribeiro, V. Sencadas, J.L.G. Ribelles, S. Lanceros-Méndez, Soft Mater. 8, 274 (2010)

28. V. Sencadas, D.M. Correia, C. Ribeiro et al., Polym. Test. 31, 1062 (2012). doi:10.1016/j.polymertesting.2012.07.010

29. V. Sencadas, C. Ribeiro, J. Nunes-Pereira, V. Correia, S. LancerosMéndez, Appl. Phys. A, Mater. Sci. Process. 109, 685 (2012). doi: 10.1007/s00339-012-7101-5

30. R. Clarisse, S. Vitor, C. Carlos Miguel, R. José Luís Gómez, L.-M. Senentxu, Sci. Technol. Adv. Mater. 12, 015001 (2011)

31. A. Arinstein, E. Zussman, Phys. Rev. E 76, 056303 (2007)

32. S. Koombhongse, W. Liu, D.H. Reneker, J. Polym. Sci., Part B, Polym. Phys. 39, 2598 (2001). doi:10.1002/polb.10015

33. X.-H. Qin, Y.-Q. Wan, J.-H. He, J. Zhang, J.-Y. Yu, S.-Y. Wang, Polymer 45, 6409 (2004). doi:10.1016/j.polymer.2004.06.031

34. S. Zhao, X. Wu, L. Wang, Y. Huang, J. Appl. Polym. Sci. 91, 242 (2004). doi:10.1002/app.13196

35. K. Gao, X. Hu, C. Dai, T. Yi, Mater. Sci. Eng. B 131, 100 (2006). doi:10.1016/j.mseb.2006.03.035

36. M.M. Demir, I. Yilgor, E. Yilgor, B. Erman, Polymer 43, 3303 (2002). doi:10.1016/s0032-3861(02)00136-2

37. S. Megelski, J.S. Stephens, D.B. Chase, J.F. Rabolt, Macromolecules 35, 8456 (2002). doi:10.1021/ma020444a

38. V. Sencadas, D.M. Correia, A. Areias et al., Carbohydr. Polym. (2011). doi:10.1016/j.carbpol.2011.09.017

39. R. Clarisse et al., Sci. Technol. Adv. Mater. 12, 015001 (2011)

40. X.M. Mo, C.Y. Xu, M. Kotaki, S. Ramakrishna, Biomaterials 25, 1883 (2004). doi:10.1016/j.biomaterials.2003.08.042

41. P.J. Flory, Principles of Polymer Chemistry (Cornell University Press, Ithaca, 1953)

42. C.M. Ofner III, W.A. Bubnis, Pharm. Res. 13, 1821 (1996). doi:10. 1023/a:1016029023910

43. G. Ceccorulli, M. Scandola, G. Pezzin, Biopolymers 16, 1505 (1977). doi:10.1002/bip.1977.360160710

44. V. Samouillan, F. Delaunay, J. Dandurand et al., J. Funct. Biomater. 2, 230 (2011)

45. L. Debelle, A.J.P. Alix, M.-P. Jacob et al., J. Biol. Chem. 270, 26099 (1995). doi:10.1074/jbc.270.44.26099

46. W.F. Daamen, J.H. Veerkamp, J.C.M. van Hest, T.H. van Kuppevelt, Biomaterials 28, 4378 (2007). doi:10.1016/j.biomaterials. 2007.06.025

47. M.-C. Popescu, C. Vasile, O. Craciunescu, Biopolymers 93, 1072 (2010). doi:10.1002/bip.21524

48. B.B. Aaron, J.M. Gosline, Biopolymers 20, 1247 (1981). doi:10. 1002/bip.1981.360200611 